\title{
High frequencies of plexiform neurofibromas, mental retardation, learning difficulties, and scoliosis in Brazilian patients with neurofibromatosis type 1
}

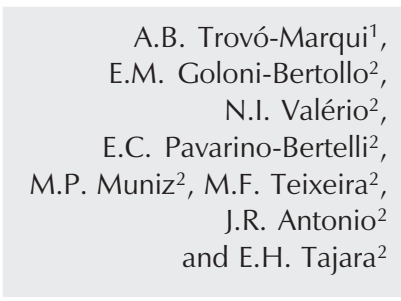

\author{
'Departamento de Biologia, Universidade Estadual Paulista, \\ São José do Rio Preto, SP, Brasil \\ ${ }^{2}$ Programa NF1, Departamento de Biologia Molecular, \\ Faculdade de Medicina de São José do Rio Preto, \\ São José do Rio Preto, SP, Brasil
}

Correspondence

E.H. Tajara

Departamento de Biologia Molecular

Faculdade de Medicina

15090-000 São José do Rio Preto, SP

Brasil

Fax: +55-17-234-6407

E-mail: tajara@famerp.br

Research supported by FAPESP (No. 99/02819-8), CNPq and CAPES.

Received November 19, 2004

Accepted June 27, 2005

\begin{abstract}
A clinical study of Brazilian patients with neurofibromatosis type 1 (NF1) was performed in a multidisciplinary Neurofibromatosis Program called CEPAN (Center of Research and Service in Neurofibromatosis). Among 55 patients (60\% females, $40 \%$ males) who met the $\mathrm{NIH}$ criteria for the diagnosis of NF1, $98 \%$ had more than six café-aulait patches, $94.5 \%$ had axillary freckling, $45 \%$ had inguinal freckling, and $87.5 \%$ had Lisch nodules. Cutaneous neurofibromas were observed in $96 \%$, and $40 \%$ presented plexiform neurofibromas. A positive family history of NF1 was found in $60 \%$, and mental retardation occurred in $35 \%$. Some degree of scoliosis was noted in $49 \%, 51 \%$ had macrocephaly, $40 \%$ had short stature, $76 \%$ had learning difficulties, and $2 \%$ had optic gliomas. Unexpectedly high frequencies of plexiform neurofibromas, mental retardation, learning difficulties, and scoliosis were observed, probably reflecting the detailed clinical analysis methods adopted by the Neurofibromatosis Program. These same patients were screened for mutations in the GAP-related domain/GRD (exons 20-27a) by single-strand conformation polymorphism. Four different mutations (Q1189X, 3525-3526delAA, E1356G, c.4111-1G $>$ A) and four polymorphisms (c.3315-27G >A, V1146I, V1317A, c.4514+11C $>$ G) were identified. These data were recently published.
\end{abstract}

\section{Introduction}

Neurofibromatosis type 1 [NF1; online Mendelian inheritance in man (OMIM 162200)] is a common autosomal dominant genetic disorder with an incidence of ap-
Key words

- Plexiform neurofibroma

- Mental retardation

- Learning difficulties

- Scoliosis
- Neurofibromatosis type I proximately 1 in 3,000. It is characterized by multiple café-au-lait spots, freckling, Lisch nodules, multiple skin neurofibromas, skeletal dysplasia, and optic gliomas (1). Learning disabilities have also been observed in patients with different inactivating mutations 
and even in NF1 mutant flies and mice $(2,3)$. Relatively few data on learning disability based on IQ tests have been reported in molecular or clinical studies on neurofibromatosis.

The NF1 gene was localized in the region $17 \mathrm{q} 11.2$ (4), and its penetrance is virtually $100 \%$. Approximately $50 \%$ of the cases represent new mutations, and the expression of the disease is highly variable, both between and within families (1). Because of this variability, population study data are especially valuable to improve genetic counseling for NF1 families and eventually the management of the patients.

With the aim of improving the care given to neurofibromatosis patients, a multidisciplinary neurofibromatosis group called CEPAN (Center of Research and Service in Neurofibromatosis) was created in the Department of Molecular Biology, School of Medicine at São José do Rio Preto, SP, Brazil. The group comprises geneticists, ophthalmologists, dermatologists, neurologists, radiologists, gynecologists, cardiologists, otorhinolaryngologists, pathologists, orthopedists, and psychologists who have established expertise and experience and who have produced publications on NF1 (5-7).

In the present study, we evaluated the clinical features of 55 Brazilian NF1 patients referred to CEPAN by specialists from different clinical areas.

\section{Material and Methods}

Fifty-five patients were classified as having NF1 according to the criteria of the National Institutes of Health (NIH) (8). The NIH criteria include at least two of the following findings: 6 or more café-au-lait spots larger than $5 \mathrm{~mm}$ in diameter in prepubertal subjects and larger than $15 \mathrm{~mm}$ in postpubertal subjects, 2 or more neurofibromas or 1 plexiform neurofibroma, intertriginous freckling, distinctive bone lesions (sphenoid wing dysplasia or pseudoarthrosis), 2 or more Lisch nodules, an optic glioma, or a first-degree relative diagnosed with NF1. Samples from these patients were previously analyzed by molecular biology techniques and the data were recently published (9).

The patients were often referred to CEPAN by dermatologists, but also by general practitioners and specialists from different clinical areas. All subjects were first examined by a general practitioner of the ambulatory care team at the Medical School Hospital of São José do Rio Preto. Each patient's diagnosis was reassessed at CEPAN, and clinical and genetic details were fully documented. The clinical study was performed in accordance with institutional and national review board-approved protocols and written informed consent was obtained from all patients or persons responsible.

A full ophthalmologic evaluation including slit lamp examination for the detection of Lisch nodules was performed. Cognitive functions were assessed using the Wechsler Intelligence Scale for Children or the Wechsler Adult Intelligence Scale tests, and mental retardation was defined as an IQ $<70$ (10). The patients' stature was measured using a stadiometer, and the occipitofrontal circumference (OFC) was measured at the largest diameter over the occiput and forehead. Standard population values for stature and OFC by age were obtained from the 1966 Tanner-Whitehouse Table (11). Bone abnormalities were investigated by $\mathrm{X}$-rays of the chest, cranium, spine, and upper and lower limbs (except hands, wrists and ankles). All patients were submitted to an electrocardiogram and electroencephalogram.

Data were analyzed statistically according to the log scale of family income. Family income was used as a socioeconomic status indicator. Using the raw scale this variable did not follow Gauss distribution, which was achieved with the log scale. Person's correlation was used to assess association between IQ values and log family income. To compare mean log family income according 
to short stature and learning difficulty we used a two-sample $t$-test with Welch correction for the degrees of freedom. To assess the level of mental retardation an exact $95 \%$ confidence interval was calculated.

\section{Results}

Fifty-five NF1 patients were assessed during the 24-month period from June 2001 to June 2003. The frequencies of clinical manifestations are summarized in Table 1. The group of patients included 22 males and 33 females. Their mean age was 33 years (range: 2-68 years) at the time of examination and 12 years (range: $1-40$ years) at the onset of symptoms, defined as the presence of six or more café-au-lait spots and/or two or more neurofibromas. Thirty-three probands $(60 \%)$ had an affected first-degree relative (parent or sibling or both).

Six or more café-au-lait spots were found in $98 \%$ of NF1 patients. Cutaneous, plexiform and eyelid neurofibromas were present in a total of 96,40 , and $17 \%$ of patients, respectively. Axillary freckling was present in $94.5 \%$ of patients and inguinal freckling was present in $45 \%$. Lisch nodules were found in $87.5 \%$. The incidences of macrocephaly $(51 \%)$ and pterygium of the eye (24\%) were high in this cohort while optic glioma was observed in one case. Orthopedic abnormalities including kyphosis, kyphoscoliosis and pectus excavatum were found in about $20 \%$ of patients, whereas scoliosis was present in $49 \%$. Other complications of NF1 (sinus tachycardia, headache and respiratory problems) were also common.

Of 48 patients whose height was documented, $19(40 \%)$ had short stature $(<3$ percentile). Cognitive deficits such as mental retardation and learning difficulties were observed in 35 and $76 \%$ of patients, respectively. Because, short stature and cognitive deficits may be affected by family income, statistical tests were performed, showing no evidence of correlation between IQ values and $\log$ family income $(r=0.26 ; \mathrm{P}=0.20)$ and no evidence of difference between $\log$ family income means according to learning difficulty $(\mathrm{P}=0.67)$. However, there was evidence of a lower mean log family income

Table 1. Frequencies of the main clinical features of 55 Brazilian patients with neurofibromatosis type 1 (NF1).

\begin{tabular}{|c|c|}
\hline Features & Frequency \\
\hline \multicolumn{2}{|l|}{ Sex } \\
\hline M & $40 \%(22 / 55)$ \\
\hline $\mathrm{F}$ & $60 \%(33 / 55)$ \\
\hline Family history of NF1 & $60 \%(33 / 55)$ \\
\hline \multicolumn{2}{|l|}{ Age at onset of symptoms } \\
\hline$\leq 5$ years & $29 \%(15 / 52)$ \\
\hline$>5$ years & $71 \%(37 / 52)$ \\
\hline \multicolumn{2}{|l|}{ Age at time of examination } \\
\hline$<5$ years & $5.5 \%(3 / 55)$ \\
\hline $5-18$ years & $14.5 \%(8 / 55)$ \\
\hline$>18$ years & $80 \%(44 / 55)$ \\
\hline$\geq 6$ café-au-lait spots & $98 \%(54 / 55)$ \\
\hline$\geq 2$ cutaneous neurofibromas & $96 \%(53 / 55)$ \\
\hline Plexiform neurofibroma (s) & $40 \%(22 / 55)$ \\
\hline \multicolumn{2}{|l|}{ Freckling } \\
\hline Axillary & $94.5 \%(52 / 55)$ \\
\hline Inguinal & $45 \%(14 / 31)$ \\
\hline$\geq 2$ Lisch nodules & $87.5 \%(42 / 48)$ \\
\hline Short stature (<3rd percentile) & $40 \%(19 / 48)$ \\
\hline Macrocephaly (98th percentile) & $51 \%(23 / 45)$ \\
\hline \multicolumn{2}{|l|}{ IQ tests } \\
\hline Normal intelligence $(I Q \geq 85)$ & $22.5 \%(9 / 40)$ \\
\hline Borderline intelligence $(70 \leq \mathrm{IQ}<85)$ & $42.5 \%(17 / 40)$ \\
\hline Mental retardation $(\mathrm{IQ}<70)$ & $35 \%(14 / 40)$ \\
\hline Learning difficulties & $76 \%(38 / 50)$ \\
\hline \multicolumn{2}{|l|}{ Other features } \\
\hline Pterygium (eye) & $24 \%(11 / 46)$ \\
\hline Eyelid neurofibroma & $17 \%(8 / 48)$ \\
\hline Optic glioma & $2 \%(1 / 47)$ \\
\hline Scoliosis & $49 \%(26 / 53)$ \\
\hline Pectus excavatum & $23 \%(12 / 53)$ \\
\hline Kyphoscoliosis & $19 \%(10 / 53)$ \\
\hline Kyphosis & $17 \%(9 / 53)$ \\
\hline Sinus tachycardia & $17 \%(7 / 42)$ \\
\hline Headache & $45.5 \%(25 / 55)$ \\
\hline Respiratory problems & $22 \%(12 / 55)$ \\
\hline
\end{tabular}

The numbers in parentheses indicate the patients with the feature/total of patients analyzed for the feature. When the number is less than the total number of individuals in the study (55 patients) this is due to the fact that the response was coded as "unknown" and these individuals were not included in the table. $I Q=$ intelligence quotient. 
in the short stature group $(\mathrm{P}=0.20)$. The estimate of the level of mental retardation was $35 \%$ with a $95 \%$ confidence from 21 to $52 \%$.

\section{Discussion}

We have reported the clinical features of $55 \mathrm{NF} 1$ patients. This report exemplifies the clinical heterogeneity of a population with NF1 and highlights similar and different features between this series of Brazilian patients and other groups of patients.

Many clinical features of the patients were similar to those reported in the literature (Table 2). Indeed, as reported by others $(12,13)$, café-au-lait spots were the most common manifestation, found in 54 of our 55 patients (98\%). This feature is usually the first sign in young children and is considered to be the most helpful one leading to diagnosis. Café-au-lait spots are not only found in NF1 patients, and about $20 \%$ of individuals in the general population have one or two such skin lesions. Although clinically similar in both groups, the number of café-au-lait spots is significantly higher in NF1 patients (1).

Table 2. Comparison of the frequencies (\%) of neurofibromatosis type 1 (NF1) features in eleven studies with the data reported here.

\begin{tabular}{|c|c|c|c|c|c|c|c|c|c|c|c|c|}
\hline \multirow[t]{2}{*}{ Features } & \multicolumn{12}{|c|}{$\begin{array}{c}\text { Reference } \\
\text { (number of patients) }\end{array}$} \\
\hline & $\begin{array}{c}23 \\
(1728)\end{array}$ & $\begin{array}{c}15 \\
(953)\end{array}$ & $\begin{array}{c}13 \\
(523)\end{array}$ & $\begin{array}{c}25 \\
(495)\end{array}$ & $\begin{array}{c}26 \\
(238)\end{array}$ & $\begin{array}{c}21 \\
(203)\end{array}$ & $\begin{array}{c}16 \\
(200)\end{array}$ & $\begin{array}{c}12 \\
(195)\end{array}$ & $\begin{array}{c}14 \\
(135)\end{array}$ & $\begin{array}{c}35 \\
(131)\end{array}$ & $\begin{array}{c}36 \\
(91)\end{array}$ & $\begin{array}{c}\text { Present study } \\
\text { (55) }\end{array}$ \\
\hline $\mathrm{CAL}$ & 89 & 100 & 98 & 95 & NA & 78 & 95.5 & 98 & 84 & NA & 82 & 98 \\
\hline NF & 54 & NA & NA & 50 & NA & NA & 49 & NA & NA & NA & 93 & 96 \\
\hline Plexiform NF & 23 & 40 & 15 & 32 & NA & 16 & 25 & NA & 32 & NA & NA & 40 \\
\hline Lisch nodules & 59 & 84 & 63 & 94 & NA & NA & 66 & 93 & 85 & NA & NA & 87.5 \\
\hline \multicolumn{13}{|l|}{ Freckling } \\
\hline axillary & NA & NA & 84 & NA & NA & NA & 84 & NA & NA & NA & NA & 94.5 \\
\hline inguinal & NA & NA & 42 & NA & NA & NA & 52 & NA & NA & NA & NA & 45 \\
\hline Pseudoarthrosis & 2 & 3 & 2 & 3 & 3 & NA & 3 & NA & 4 & 0 & NA & 0 \\
\hline Scoliosis & 24 & 25 & 12 & 23 & 29 & 16 & 20.5 & NA & 10 & 5 & $\geq 10$ & 49 \\
\hline Pectus excavatum & NA & NA & NA & NA & NA & NA & 7 & NA & NA & NA & $\mathrm{NA}$ & 23 \\
\hline Kyphoscoliosis & NA & NA & NA & NA & NA & NA & NA & 13 & NA & NA & NA & 19 \\
\hline Optic glioma & 4 & NA & 5 & 10 & 15 & NA & 9 & 10 & 2 & 2 & 0 & 2 \\
\hline Macrocephaly & NA & NA & NA & 38 & NA & NA & 43 & 36 & 45 & NA & NA & 51 \\
\hline Short stature & NA & NA & NA & 18 & NA & NA & 27 & NA & 34 & NA & NA & 40 \\
\hline Learning disabilities & NA & NA & 62 & NA & 30 & NA & 45 & NA & 30 & NA & NA & 76 \\
\hline Mental retardation & NA & NA & NA & NA & NA & NA & NA & 14 & NA & NA & NA & 35 \\
\hline Seizures & 6 & 6 & 4 & 5 & 3 & NA & 3.5 & NA & 7 & 6 & $3-9$ & 11 \\
\hline Headache & NA & NA & NA & 22 & NA & NA & 9 & NA & NA & NA & NA & 45.5 \\
\hline Hydrocephalus & 4 & NA & NA & 3 & NA & NA & NA & 5 & NA & NA & NA & 0 \\
\hline Psychiatric disorder & NA & NA & NA & NA & NA & NA & 2.5 & NA & NA & NA & NA & 2 \\
\hline Facial asymmetry & 8 & NA & NA & NA & NA & NA & 1 & NA & NA & NA & NA & 4 \\
\hline Precocious puberty & 3.5 & NA & NA & 5 & NA & NA & 1.5 & NA & NA & NA & NA & 0 \\
\hline Delayed puberty & NA & NA & NA & NA & NA & NA & 0.5 & NA & NA & NA & NA & 0 \\
\hline Constipation & NA & NA & NA & NA & NA & NA & 2 & NA & NA & NA & NA & 14.5 \\
\hline Hypertension & 4 & NA & NA & 4 & NA & NA & 3.5 & NA & NA & NA & NA & 11 \\
\hline Noonan phenotype & 4 & NA & NA & 9 & NA & NA & 7 & NA & NA & NA & NA & 0 \\
\hline Malignancy & 5 & 4 & NA & 5 & NA & 5 & NA & NA & NA & NA & 10 & 0 \\
\hline CNS tumors & 2 & NA & 9 & 3 & 0 & NA & 2.5 & 5 & 0 & NA & NA & 4 \\
\hline Neurofibrosarcoma & NA & NA & NA & NA & NA & NA & 1 & 0.5 & NA & NA & NA & 0 \\
\hline Xanthogranulomas & 2 & 2 & NA & NA & NA & NA & 2 & NA & 1 & NA & NA & 0 \\
\hline
\end{tabular}

$\mathrm{NA}=$ not analyzed; CAL = café-au-lait spots; NF = neurofibromas; CNS = central nervous system. 
Almost all our patients exhibited axillary freckling $(94.5 \%)$, while 14 of $31(45 \%)$ showed inguinal freckling. The frequency of Lisch nodules (iris hamartomas) was also high $(87.5 \%)$ in the cases submitted to slit lamp examination. Both freckling and Lisch nodule data were similar to literature reports (13-15).

Some of the NF1 features, such as macrocephaly, short stature and thoracic abnormalities, were present in a significant number of our patients. Macrocephaly and short stature have usually been detected in about 30 to $40 \%$ of NF1 patients $(14,16)$. In the present study, 23 of 45 cases (51\%) showed an OFC above the 98th percentile, and $40 \%$ were at or below the 3 rd percentile in height.

Plexiform neurofibroma of the head, early or delayed puberty, optic glioma or hydrocephalus occasionally affect OFC measurements (17). However, among NF1 patients, an increased OFC has frequently no obvious cause and appears to result from overgrowth of the brain. In the present study, no cranial abnormality was found by X-rays. For detection of optic glioma, all patients were investigated by campimetry and suspected cases were also submitted to computed tomography. A single case of optic glioma was detected, and had no effect on the frequency of macrocephaly.

Pseudoarthrosis, early or delayed puberty, optic glioma, scoliosis or vertebral dysplasia may also influence stature (17). Actually, there were no cases of pseudoarthrosis and early or delayed puberty in our cohort and, excluding our patients with scoliosis or vertebral dysplasia $(\mathrm{N}=9)$, short stature was found in only a small number of cases $(21 \%)$. In these patients, the short stature affected the whole skeleton in a proportionate manner, and no specific cause was apparent.

In the present study, the frequencies of respiratory problems and headache were 22 and $45.5 \%$, respectively. Respiratory problems are uncommon in NF1, but intrapulmonary neurofibromas or scoliosis may cause lung disease. Patients with NF1 may also have headaches as a result of anxiety or depression associated with the disease (18). Only one of our cases had optic glioma and one had ectropion uveae. The incidence of optic gliomas ranges from 1 to $20 \%$ in NF1 cases, but only $1-5 \%$ develop symptoms (19). Congenital ectropion uveae is occasionally associated with other ocular anomalies and with NF1 (20).

Therefore, the clinical features of the 55 patients were typical of an NF1 phenotype, although an unexpectedly higher incidence of plexiform neurofibromas, mental retardation, learning difficulties, and scoliosis was found. The incidence of plexiform neurofibromas was $40 \%$, similar to the findings of Riccardi (15), but higher than the percentage of $15-32 \%$ reported by others $(13,14,16,21$ $25)$. We also found IQ scores below 70 in $35 \%$ of the cases (14 of 40 ). Fifteen patients refused the IQ tests. Other studies have reported mental retardation frequencies ranging from 3 to $14 \%(12,15,26-33)$. Learning difficulties were also reported in 38 of 50 (76\%) patients in our study, a value higher than the percentage of 30-62\% reported by others (13,14,16,22-24,26-31,33-35). Three children in the preschool age and two illiterate patients were excluded from the analyses because of learning difficulties. In addition, $49 \%$ of our patients presented scoliosis, a much higher percentage than the 5 to $29 \%$ reported by others $(13-16,21,23,25,26,36$, 37).

Such differences probably reflect the methods used to assess the data. For example, clinical evaluation may miss some cases of plexiform neurofibromas. Magnetic resonance imaging and histopathological evaluation, as performed by Riccardi (15) and by us, should improve the diagnosis. However, our group of patients is too small to permit a definitive conclusion. With respect to scoliosis, the high incidence found in our sample may be due to evaluation by $\mathrm{X}$-ray and therefore the inclusion of mild 
cases, reinforcing the idea that differences in the frequencies of NF1 manifestations are probably caused by the methods of assessing them.

The higher frequency of mental retardation and learning difficulties in our study may reflect the socioeconomic and cultural status of the cohort. Also, this higher frequency may be due to limited psychosocial and environmental stimulation related to the lack of specialized patient and family support in Brazil. However, there was no significant association between IQ values, learning difficulties and family income, a socioeconomic status indicator. Similar results were reported by North et al. (31) and Ferner et al. (32). Also, the frequency of mental retardation in NF1 patients was much higher than expected for the Brazilian population (35 vs 5\%) according to Tramontina et al. (38).

Descheemaeker et al. (39) observed that the mean full-scale IQ was significantly lower in the NF1 microdeletion group (76.0) compared with the non-microdeletion group (88.5). Our NF1 patients were not screened for this alteration. Thus, it is possible that cases with microdeletion contributed to the higher frequency of mental retardation observed in our cohort.

Several studies have shown that mutations in the NF1 gene cause abnormalities in cell growth and differentiation and lead to a variety of learning disabilities. Neurofibromin has several biochemical functions, such as Ras-guanosine triphosphatase activity, adenylate cyclase modulation, and microtu- bule binding, all of which could be critical for brain function. A recent study has suggested that the learning disabilities associated with NF1 are caused by excessive Ras activity that leads to increased $\gamma$-aminobutyric acid inhibition and to decreased longterm potentiation (40).

Apart from differences in methodology, a precise comparison of different studies is difficult because the frequencies of most NF1 features change with age, and the age distributions of the cohorts probably differ. Moreover, different criteria for the diagnosis and definition of disease manifestations have been used.

Even considering these differences, our study was able to show that mental retardation is common in NF1. In addition to mental retardation, learning difficulties, plexiform neurofibromas, and scoliosis were also common, showing that these features, if accurately investigated, are more common in NF1 than previously thought. This insight may be valuable for genetic counseling and for the management of NF1 patients.

\section{Acknowledgments}

We are grateful to the NF1 patients for their willing participation in this study. We also thank our colleague Nicole S.L. Grosso, for critically reading the English manuscript and Prof. José Antonio Cordeiro (Faculdade de Medicina de São José do Rio Preto, São José do Rio Preto, SP, Brazil) for statistical analysis.

\section{References}

1. Huson SM \& Hughes RAC (1994). The Neurofibromatoses: A Pathogenetic and Clinical Overview. Chapman and Hall Medical, London, UK.

2. Guo HF, Tong J, Hannan F et al. (2000). A neurofibromatosis-1regulated pathway is required for learning in Drosophila. Nature, 403: 895-898.

3. Costa RM, Yang T, Huynh DP et al. (2001). Learning deficits, but normal development and tumor predisposition, in mice lacking exon 23a of N11. Nature Genetics, 27: 399-405.

4. Barker D, Wright E, Nguyen K et al. (1987). Gene for von Recklinghausen neurofibromatosis is in the pericentromeric region of chromosome 17. Science, 236: 1100-1102.

5. Goloni-Bertollo EM, Antonio JR \& Varella-Garcia M (1994). Avaliação genético-clínica em neurofibromatose. Anais Brasileiros de Dermatologia, 69: 311-320.

6. Muniz MP, Almeida JRM, Aires SA et al. (2002). Prevalência de 
achados radiográficos da neurofibromatose tipo 1 - Estudo de 82 casos. Radiologia Brasileira, 35: 65-70.

7. Viana ACS, Liberatore Jr RDR \& Goloni-Bertollo EM (2004). Puberdade e crescimento em crianças e adolescentes com neurofibromatose tipo 1. Revista da Associação Médica Brasileira, 50: $163-166$

8. NIH (1988). Consensus Development Conference Neurofibromatosis. Archives of Neurology, 45: 575-578.

9. Trovó AB, Goloni-Bertollo EM, Mancini UM et al. (2004). Mutational analysis of the GAP-related domain of the neurofibromatosis type 1 gene in Brazilian NF1 patients. Genetics and Molecular Biology, 27: 326-330.

10. North KN, Riccardi VM, Samango-Sprouse C et al. (1997). Cognitive function and academic performance in neurofibromatosis type 1: Consensus statement from the NF1 Cognitive Disorders Task Force. Neurology, 48: 1121-1127.

11. Jones KL (1988). Smith's Recognizable Patterns of Human Malformation. 4th edn. W.B. Saunders Co., Philadelphia, PA, USA.

12. Overweg-Plandsoen WC, Weersink RG, Sillevis Smitt JH et al. (1997). Neurofibromatosis type 1: a survey of 195 patients. Nederlands Tijdschrift Voor Geneeskunde, 141: 624-629.

13. McGaughran JM, Harris DI, Donnai D et al. (1999). A clinical study of type 1 neurofibromatosis in north west England. Journal of Medical Genetics, 36: 197-203.

14. Huson SM, Harper PS \& Compston DA (1988). Von Recklinghausen neurofibromatosis. A clinical and population study in south-east Wales. Brain, 111: 1355-1381.

15. Riccardi VM (1992). Neurofibromatosis: Phenotype, Natural History and Pathogenesis. 2nd edn. Johns Hopkins University Press, Baltimore, MD, USA.

16. North K (1993). Neurofibromatosis type 1: review of the first 200 patients in an Australian clinic. Journal of Child Neurology, 8: 395402.

17. Szudek J, Birch P \& Friedman JM (2000). Growth in North American white children with neurofibromatosis 1 (NF1). Journal of Medical Genetics, 37: 933-938.

18. Ruggieri (1999). The different forms of neurofibromatosis. Childs Nervous System, 15: 295-308.

19. Listernick R, Louis DN, Packer RJ et al. (1997). Optic pathway glioma in children with neurofibromatosis type 1: consensus statement from the Optic Pathway Glioma Task Force. Annals of Neurology, 41: 143-149.

20. Trovó-Marqui AB, Goloni-Bertollo EM, Teixeira MF et al. (2004). Presence of the R1748X mutation in the NF1 gene in a Brazilian patient with ectropion uveae. Ophthalmic Research, 36: 349-352.

21. Crowe FW, Schull WJ \& Neel JV (1956). A Clinical Pathological and Genetic Study of Multiple Neurofibromatosis. Charles C. Thomas, Springfield, IL, USA.

22. Wolkenstein $P$, Frèche $B$, Zeller $J$ et al. (1996). Usefulness of screening investigations in neurofibromatosis type 1: a study of 152 patients. Archives of Dermatology, 132: 1333-1336.

23. Friedman JM \& Birch PH (1997). Type 1 neurofibromatosis: a descriptive analysis of the disorder in 1,728 patients. American Journal of Medical Genetics, 70: 138-143.

24. Cnossen MH, de Goede-Bolder A, van den Broek KM et al. (1998).
A prospective 10 year follow up study of patients with neurofibromatosis type 1. Archives of Disease in Childhood, 78: 408-412.

25. Young H, Hyman S \& North K (2002). Neurofibromatosis 1: Clinical review and exceptions to the rules. Journal of Child Neurology, 17: 613-621.

26. Riccardi VM \& Eichner JE (1986). Neurofibromatosis. Phenotype, Natural History and Pathogenesis. Johns Hopkins University, Baltimore, MD, USA.

27. Wadsby M, Lindenhammer H \& Eeg-Olofsson O (1989). Neurofibromatosis in childhood: neuropsychological aspects. Neurofibromatosis, 2: 251-260.

28. Legius E, Descheemaeker MJ, Spaepen A et al. (1994). Neurofibromatosis type 1 in childhood: a study of the neuropsychological profile in 45 children. Genetic Counseling, 5: 51-60.

29. Moore BD, Ater JL, Needle MN et al. (1994). Neuropsychological profile of children with neurofibromatosis, brain tumor, or both. Journal of Child Neurology, 9: 368-377.

30. North K, Joy P, Yuille D et al. (1994). Specific learning disability in children with neurofibromatosis type 1: Significance of MRI abnormalities. Neurology, 44: 878-883.

31. North K, Joy P, Yuille D et al. (1995). Cognitive function and academic performance in children with neurofibromatosis type 1. Developmental Medicine and Child Neurology, 37: 427-436.

32. Ferner RE, Hughes RAC \& Weinman J (1996). Intellectual impairment in neurofibromatosis 1. Journal of the Neurological Sciences, 138: 125-133.

33. Moore BD, Slopis JM, Schomer D et al. (1996). Neuropsychological significance of areas of high signal intensity on brain magnetic resonance imaging scans of children with neurofibromatosis. $\mathrm{Neu}$ rology, 46: 1660-1668.

34. Stine SB \& Adams WV (1989). Learning problems in neurofibromatosis patients. Clinical Orthopaedics, 245: 43-48.

35. Descheemaeker MJ, Ghesquière P, Symons H et al. (2005). Behavioural, academic and neuropsychological profile of normally gifted neurofibromatosis type I children. Journal of Intellectual Disability Research, 49: 33-46.

36. Carey JC, Laub JM \& Hall BD (1979). Penetrance and Variability in Neurofibromatosis: A Genetic Study of 60 Families. Alan R. Liss, Inc., New York, for the National Foundation - March of Dimes, BD:OAS XV (5B), 271-281.

37. Samuelsson B \& Axelsson R (1981). Neurofibromatosis: A clinical and genetic study of 96 cases in Gothenburg, Sweden. Acta Dermato-Venereologica, 95 (Suppl): 67-71.

38. Tramontina S, Martins S, Michalowski MB et al. (2002). Estimated mental retardation and school dropout in a sample of students from state public schools in Porto Alegre, Brazil. Revista Brasileira de Psiquiatria, 24: 177-181.

39. Descheemaeker MJ, Roelandts K, De Raedt T et al. (2004). Intelligence in individuals with a neurofibromatosis type 1 microdeletion. American Journal of Medical Genetics, 131A: 325-326.

40. Costa RM \& Silva AJ (2002). Molecular and cellular mechanisms underlying the cognitive deficits associated with neurofibromatosis 1. Journal of Child Neurology, 17: 622-626 (Discussion 627-629, 646-651). 